\title{
Possibilities of image analysis for quality wood sorting
}

\author{
Miloš Gejdošํㅜ Tomáš Gergel² *, Tomáš Bucha², Zuzana Vyhnáliková3 \\ ${ }^{1}$ Technical University in Zvolen, Faculty of Forestry, T. G. Masaryka 24, SK - 96001 Zvolen, Slovak Republic \\ ${ }^{2}$ National Forest Centre - Forest Research Institute Zvolen, T. G. Masaryka 2175/22, SK-960 01 Zvolen, Slovak Republic \\ ${ }^{3}$ Technical University in Zvolen, The Institute of Foreign Languages, T. G. Masaryka 24, SK-960 01 Zvolen, Slovak Republic
}

\begin{abstract}
Wood assessment optimization should be the top priority of the forestry subjects that are fundamentally dependent on the income from its sale. The aim of this paper is to analyse the beech, oak and ash tree logs that were categorized into quality classes according to the size of one of the qualitative characters related to the surface area (false heartwood, rot). The classical methodology used in forestry was compared with the application of ImageJ software. In total, thirty logs were analysed. The characters of false heartwood and rot were chosen and evaluated according to their size on the log end. There were no other characters that obstructed the categorization into quality classes. The ImageJ software application led to improved assessment (transfer to a higher quality class) in $56 \%$ of the logs. The volume of the evaluated assortments was $18.43 \mathrm{~m}^{3}$. The total difference in the value of the assortments with the ImageJ software application reached $+€ 70.44(+4.7 \%)$. The analysis therefore confirmed that in case of a considerable irregularity in a qualitative character (when the surface area of the character significantly differs from the circumscribed circular surface), the standard STN EN 1309-3 methodology systematically overvalues the surface area of this character. That affects the assessment potential of the specific log.
\end{abstract}

Key words: log quality; wood sorting; image analysis; wood proporties

Editor: Miloš Pánek

\section{Introduction}

Evaluation of the produced wood consists of assessing the size of its qualitative characters and technical conditions that define the allowed or unallowed size of these characters. Since the qualitative wood evaluation according to its positive qualitative characters is not yet possible, it is evaluated only according to the occurrence and size of the negative qualitative characters (wood defects). This evaluation method develops a quality framework that constitutes the basis for the sellerbuyer relationship. The seller and the buyer can stipulate specific conditions as well as price levels depending on the basic quality sorting defined by the technical conditions (Hein et al. 2007; Gejdoš \& Danihelová 2015). For the optimization of the produced wood evaluation it is necessary to know the qualitative characters of the wood and their measurement and assessment methods. In the European trade area they are defined primarily in the standards STN EN 844-8 "Round and sawn timber. Terminology. Part 8: Terms relating to features of round timber" and STN EN 1309-3 "Round and sawn timber. Methods of measurements. Part 3: Features and biologi- cal degradations". In the forestry practice, the qualitative characters are assessed and measured either manually (by visual evaluation), or electronically (mainly through scanners). The electronic evaluations and measurements require the investment in devices as well as construction works that are not profitable in forestry. Usually they are bought only by timber processors with a high concentration of wood stock inventories where the application of electronic devices increases the economic profit (Gergel' et al. 2019). There is a relatively wide range of software tools that offer a simplified analysis of qualitative characters. Most of them are paid applications. However, there are also free software tools that can evaluate the surface area of certain qualitative characters from high-quality photographs (Gejdoš et al. 2014). The irregular shape of the qualitative characters evaluated according to their surface area (like rot, discolouration, false heartwood, spalting, reaction wood) can cause significant measurement deviations, since according to the STN EN 1309-3 the diameter of the circle circumscribing such a character has to be measured. This method significantly overvalues the surface area of the character. Software tools use photographing analysis that enables considerably more

*Corresponding author. Tomáš Gergel', e-mail:gergel@nlcsk.org, phone: +421 0455314128 
accurate evaluation of qualitative characters, as they can determine the exact value of such a character on the surface of the log. The aim of this paper is to verify whether the application of the ImageJ software tool for the qualitative analysis of the selected broad-leaved trees logs is a suitable alternative for qualitative assessment of wood. The classical approach used in forestry was compared to the application of ImageJ software. The software tool should enable economically more effective assessment of raw wood assortments, where the size of qualitative characters determines the categorization into quality class.

Presence of false heartwood and its percentage has a significant impact on the possibilities of its assessment and on the purpose of its use. Many authors described the efficiency of the logs with false heartwood in its processing from the sawing process to the end product: Petrás (2015) created the models for assessing the growth and production of the forest covers. Račko \& Čunderlík (2006) proved that false heartwood occurs in $1 / 3$ of the beech logs, mainly in older trees. It is caused by many factors, their influence was analysed in the papers of (Račko \& Čunderlík 2010). The authors compared age of the trees, dimension of the trees, representation of tree species in the forest cover as well as size of the tree crowns. It was concluded that the most significant factor affecting the presence and creation of the false heartwood is the age of the trees. Crown size and representation of tree species in the forest cover do not have a major influence on the false heartwood presence. A high share of the round timber with false heartwood in beech trees affects its processing into sawn timber. Popadić et al. (2014) studied the influence of the round timber sawing method with false heartwood in beech trees on its assessment. Results suggest that the largest yield was achieved when using round sawing and cant sawing. (Barański et al. 2017) and (Shahverdi et al. 2013) proved that the presence of false heartwood in the beech sawn timber greatly affects the drying process and the final quality of the sawn timber. If the beech wood is used for veneer production, the presence, percentage and shape of the false heartwood also must be taken into consideration. It is necessary to determine the optimum thickness of the beech round timber for veneer production. Bluskova et al. (2008) discovered that the most suitable round timber for veneer production is $400 \mathrm{~mm}$ thick.

This overview proves that the share of false heartwood in the beech round timber greatly affects its assessment and this character has to be taken into consideration in every stage of technological process.

\section{Material and methods}

Thirty logs in total were analysed: European beech (Fagus sylvatica) - 26 logs, sessile oak (Quercus petraea) - 3 logs, and European ash (Fraxinus excelsior) - 1 log. The amount of samples was limited to the availability of tree species in the storehouse in winter as well as to the qualitative characters crucial for their categorization. Only those logs were analysed where the qualitative categorization depended solely on one qualitative character assessed according to its size on the surface area of the log. The qualitative character in beech and ash trees was false heartwood (heartwood by ash). In oak trees it was heartwood rot.

The qualitative characters were at first measured manually according to the standard STN EN 1309-3 (Fig. 1).

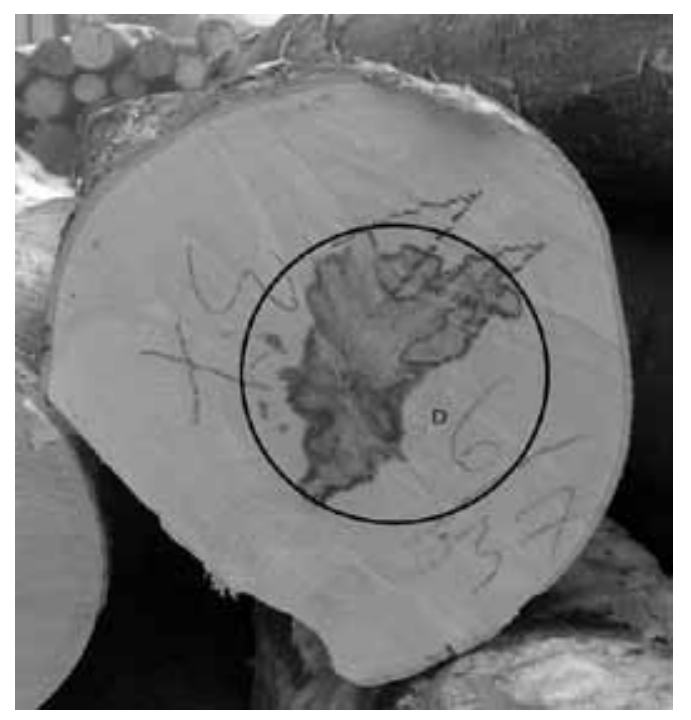

Fig. 1. Evaluation of false heartwood on beech according to STN EN 1309-3.

As an alternative for optimization of qualitative evaluation of these assortments the ImageJ software was selected. Its use and methodology of surface area assessment for the beech trees with false heartwood or other characters is described in the papers of (Gurau et al. 2013; Gejdoš et al. 2014; Phonetip et al. 2017; Potkány et al. 2018). Assessment methodology of the characters in this software was adopted from the paper by (Gejdoš et al. 2014). The assessment of the qualitative characters in the software consists of the following steps:

- Production and processing of a digital image perpendicularly to the log axis that has a qualitative character. Manual measurement of the log end diameter according to standard dendrometric rules.

- Digital image processing in the software and determination of the reference dimension (reference dimension is the diameter of the log end in centimetres) - Fig. 2a.

- Highlighting the area of the end log in software-Fig. 2 b.

- Highlighting the area of the qualitative character in software - Fig. 2c.

- Calculation of the log end area and the qualitative character area according to the reference dimension. The percentage of the surface area of the selected 
qualitative character on the log end is easily expressed by this simple process. It calculates the exact surface area of the qualitative character without overvaluation. The overvaluation caused by using the standard method is obvious also in the Fig. 1 (the "healthy" wood areas are included in the surface area of the qualitative character). Figure 2 shows the processing procedure in the ImageJ software. This procedure was used on all the analysed logs.
For simple calculations and graphical evaluation, MS Excel 2013 was used. To measure the size of false heartwood steel meter (band) was used, and to measure assortments thickness standardized calliper was used. Photographic documentation was done with digital camera NIKON D5200 with an effective megapixel count 24.1 and lens with a focal length $\mathrm{f}=18.0 \mathrm{~mm}$. Printed graphics and other evaluations were performed by the software product Image J 1.52a.
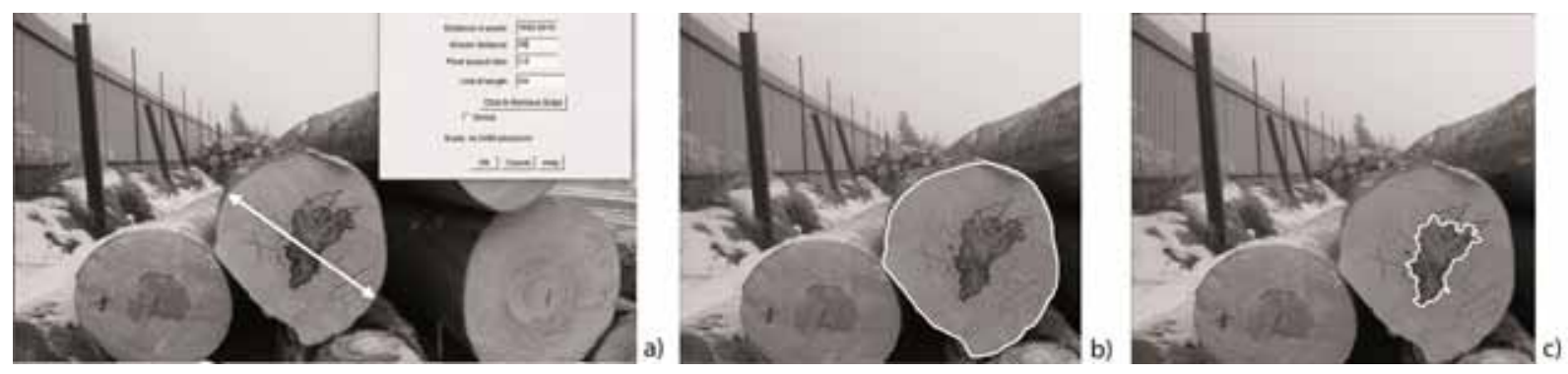

Fig. 2. Evaluation of compression wood in spruce with the ImageJ software: (a) scale determination in cm; (b) log-end area determination; (c) area of false heartwood determination.

The logs were categorized into quality classes according to the 2007 standard STN 48 0056. This standard classifies broad-leaved raw wood assortments. The determinative characters assessed according to the surface area in these quality classes are false heartwood and rot. The allowed area of these qualitative characters in round timber quality classes II. and III. is stated in Table 1. Quality class II. includes logs for peeled veneer production, logs for match production, sports equipment, technical equipment and cask production. The quality class III. wood is used mainly for sawmill processing. In higher quality classes the occurrence of these characters is not allowed. In lower quality classes it is allowed without restrictions.

For assessing the economic efficiency of the ImageJ software, the average Slovak prices from the price list of the Forest Market Information System for the fourth quarter of 2018 were used. The prices in Slovakia are stated in $€ \mathrm{~m}^{-3}$ excluding VAT at CIF level.

Volume of assortments was determined individually by the Smalian formula [1]:

$$
v=\frac{\pi}{4} \cdot \frac{d_{0}^{2}+d_{n}^{2}}{2} \cdot L
$$

Where:

$v$ - log volume in $\mathrm{m}^{3}$

$d_{0}-\log$ thickness (thicker end) in $\mathrm{m}$

$d_{n}$ - end diameter thickness (thinner end) in $\mathrm{m}$

$L$-length of $\log$ in $\mathrm{m}$.

\section{Results and discussion}

From the chosen two qualitative characters that were assessed according to the surface area and that were the only restricting characters for qualitative classification, the character false heartwood was identified in 26 beech logs and 1 ash log. The character rot was identified in 3 oak logs. The classification into corresponding quality classes in view of the qualitative characters according to the standard STN EN 1309-3 and technical conditions STN 480056 can be seen in Table 1. The assortments were assessed with the ImageJ software and in accordance with the standards. The application of the ImageJ software led to better assessment (transfer to a higher quality class) in $56 \%$ of logs. Paradoxically, the price for the quality class I. beech wood in the price list was $116.72 € \mathrm{~m}^{-3}$ without VAT and for the quality class II. beech wood $119.28 € \mathrm{~m}^{-3}$ withoutVAT. Therefore, in two cases the transfer to a higher quality class paradoxically had a negative economic impact. However, such situations occur only rarely on the market. This fact is also negatively affected by the long-term situation on the market with valuable logs and beech sawmill round timber. The processors show only little interest in these kinds of assortment. Subsequently, such paradoxes reflect in price lists and implementation of the commercial policy. Table 2 shows the amount of logs classified into the corresponding quality classes according to the standard STN 480056 (2007). The qualitative characters of the logs

Table 1. Allowed surface area of false heartwood in beech/ash and rot in oak for the quality classes II. and III. according to the standard STN 480056 (2007).

\begin{tabular}{|c|c|c|c|c|}
\hline Quality character & II. & III.A & III.B & III.C \\
\hline ond (heech ach) & Up to $1 / 3$ area & Up to $1 / 3$ area & Up to $1 / 2$ area & Allowed without restrictions \\
\hline False neartwooa (beecn, asn) & of the end diameter & of the end diameter & of the end diameter & (flame up to $1 / 2$ area) \\
\hline Rot (oak) & Not allowed & Not allowed & Not allowed & Up to $1 / 3$ area of the end diameter \\
\hline
\end{tabular}


were assessed according to the standard STN EN 1309-3 and the ImageJ software algorithm.

Table 2. Division of beech, oak and ash round timber logs into quality classes according to the standard STN 480056 (2007) using two evaluation methods.

\begin{tabular}{lcccccc}
\hline Quality class / No. of Logs & I. & II. & III.A & III.B & III.C & V. \\
\hline STN EN 1309-3 Classification & 0 & 6 & 0 & 10 & 9 & 5 \\
ImageJ Classification & 2 & 3 & 8 & 10 & 2 & 5 \\
\hline
\end{tabular}

According to the ImageJ software, the average surface area of false heartwood and rot on all log ends comprised $15.35 \%$ of the whole surface of the log end.

Table 3 shows the economic evaluation of both methods of qualitative classification of spruce logs. The volume of the evaluated assortments was $18.43 \mathrm{~m}^{3}$. The total difference in the value of the assortments with the application of the ImageJ software reached $+€ 70.44$ $(+4.7 \%)$. A change in the evaluation methodology of qualitative characters assessed according to their size can lead to a more precise evaluation of the produced raw wood assortments despite the aforementioned market paradoxes with the beech round timber.

The analysis therefore confirmed that in case of a considerable irregularity in a qualitative character (when the surface area of the character significantly differs from the circumscribed circular surface), the methodology stated in the standard STN EN 1309-3 systematically overvalues the surface area of this character. That affects the assessment potential of the specific log. In case of oak sawmill round timber the decisive character that significantly restricted qualitative classification was rot. Here the use of new methodology did not lead to qualitative shift of produced assortments. The same applied to ash logs. There was not a sufficient amount of oak and ash tree logs that could definitely prove the positive influence of the new methodology on their assessment. Since beech is the most common tree in Slovak forests where false heartwood occurs quite often, application of this evaluation method on yearly production volume of the beech assortments could lead to significant improvement in their economic assessment.

In the study of Potkány et al. (2018) this evaluation method also led to better assessment of the raw wood assortments produced from spruce sawmill round timber. The qualitative characters of reaction wood, rot and wood discolouration on sawmill round timber were assessed. One hundred logs in total were analysed. Overall, the economic assessment of the wood improved by $€ 426.68$.

In the study of Gejdoš et al. (2014) the ImageJ software analysed $63 \mathrm{logs}$ with false heartwood. Such evaluation method also led to better assessment of the wood assortments, in comparison with the classical evaluation according to the standards, by $€ 399.54$. However, this study also included logs that were categorized into quality classes not only according to the size of the qualitative characters related to the surface area. The assessed logs came mostly from tending felling. Our study analysed only the logs that were categorized into quality classes solely according to the size of the qualitative characters related to the surface area and the assessed logs came mostly from principal felling.

All studies therefore confirm that if the size of the qualitative characters related to the surface area was analysed more precisely, the qualitative classification would be more accurate and the overall assessment of the assortments would be higher. In Slovakia, the sales of the sold wood comprise almost $90 \%$ of the forestry incomes. Therefore, seeking ways to optimize the assessment of raw wood assortments should be the top priority of forestry practice and research.

\section{Conclusion}

The disadvantage of using the ImageJ software is that for the time being it is not a part of standard legislation for assessing the qualitative characters of the logs. Another disadvantage is that it is not quite possible to unify the methods of taking and evaluating photographs in the working practice (different parameters of cameras, camera angles, lighting conditions, etc.). However, it is a simple tool that could be used even in difficult conditions of forestry practice. For these purposes, there are already some similar tools used in the forms of various mobile applications or software solutions for mobile devices. In forestry, using the CT scanners and tomographs for size detection of qualitative characters is not profitable for operational and economic reasons. Incorrect qualitative assessment often leads to wrongful categorization of logs into lower quality classes and to decreased potential for higher-quality processing (Hajdúchová et al. 2016). The software possibilities are being dynamically developed

Table 3. Economic assessment of the analysed beech, oak and ash round timber logs using two evaluation methods.

\begin{tabular}{|c|c|c|c|c|c|c|c|}
\hline \multirow[b]{2}{*}{ Quality class/No. of Logs } & \multicolumn{3}{|c|}{ Price in $€ \mathrm{~m}^{-3}$} & \multirow{2}{*}{$\begin{array}{c}\text { Volume of Logs } \\
\text { according to STN EN 1309-3 } \\
{\left[\mathrm{m}^{3}\right]}\end{array}$} & \multirow{2}{*}{$\begin{array}{c}\text { Total Price in } € \mathrm{~m}^{-3 *} \\
\text { According to STN EN 1309-3 }\end{array}$} & \multirow{2}{*}{$\begin{array}{c}\text { Volume of Logs } \\
\text { according to ImageJ } \\
{\left[\mathrm{m}^{3}\right]}\end{array}$} & \multirow{2}{*}{$\begin{array}{l}\text { Total Price in } € \mathrm{~m}^{-3 *} \\
\text { according to ImageJ }\end{array}$} \\
\hline & beech & oak & ash & & & & \\
\hline I. & 116.72 & 480.16 & - & 0 & 0 & 3.11 & 363 \\
\hline II. & 119.28 & 309.99 & 200.04 & 5.18 & 617.87 & 1.6 & 190.85 \\
\hline III.A & 76.93 & 214.1 & 120.71 & 0 & 0 & 4.76 & 366.18 \\
\hline III.B & 60.02 & 164.5 & 90.74 & 5.62 & 377.02 & 5.99 & 399.22 \\
\hline III.C & 54.49 & 76.16 & 58 & 5.9 & 348.36 & 1.24 & 94.44 \\
\hline V. & 44.79 & 41.96 & 43.64 & 1.73 & 77.22 & 1.73 & 77.22 \\
\hline Total & - & - & - & 18.43 & 1420.47 & 18.43 & 1490.91 \\
\hline
\end{tabular}


also in forestry. Together with the potential for greater application increase the demands on knowledge and experience of the management and people assessing the logs. It is therefore important to be willing to implement innovations, to test them and to subsequently use them in forestry practice. At the same time it is necessary to adjust the corresponding standards, technical conditions and legislation in such a way that it will be possible to optimize the qualitative potential of raw wood assortments. However, the processors will most probably not be willing to change anything in this area because it could have a negative impact on their economic balance. Nevertheless, the results of this study show that the innovative way of assessing the qualitative characters can lead to a more accurate evaluation of qualitative characters and therefore to the optimization of raw wood assortments evaluation.

\section{Acknowledgements}

This work is part of the VEGA Nr. 1/0031/18 project Optimization of technological and work processes and risk assessment in the production of forest biomass for energy purposes, MPRVSR item 08V0301 - Research and development to promote forestry competitiveness (SLOV-LES) and OPVaI International Teaming Research Centers.

\section{References}

Barański, J., Klement, I., Vilkovská, T., Konopka, A., 2017: High temperature drying process of beech wood (Fagus sylvatica L.) with different zones of sapwood and red false heartwood. BioResources, 12:1861-1870.

Bluskova, G., Bardarov, N., Naydenova, M., 2008: Study of false heartwood in the round material for the production of plywood. In: Scientific - Technical Conference - Innovation in woodworking industry and engineering design. Yundola, p. 29-33.

STN EN 1309-3 Round and sawn timber - Methods of measurements - Part 3: Features and biological degradations, 2018, CEN, rue de Stassart 36, 1050 Bruxelles, Belgium.

Forest market information system. Available online: http://www.forestportal.sk/lesne-hospodarstvo/ informacie-o-lesoch/trhove-spravodajstvo/Pages/ informacne-listy-ltis.aspx (accessed on 12.02.2019).

Gejdoš, M., Danihelová, Z., 2015:Valuation and Timber Market in the Slovak Republic. Procedia Economics and Finance, 34:697-703.

Gejdoš, M., Suchomel, J., Potkány, M., 2014: Software "Image J" Application in Evaluating the Quality of Extracted Raw Wood Assortments. Drvna Industrija, 65:105-113.
Gergel', T., Bucha, T., Gejdoš, M., Vyhnáliková,Z., 2019: Computed tomography log scanning - high technology for forestry and forest based industry. Central European Forestry Journal, 65:51-59.

Gurau, L., Timar, M. C., Porojan, M., Ioras, F., 2013: Image Processing Method as a Supporting Tool For Wood Species Identification. Wood and Fiber Science, 45:303-313.

Hajdúchová, I., Sedliačiková, M., Halaj, D., Krištofík, P., Musa, H., Viszlai, I., 2016: The Slovakian ForestBased Sector in the Context of Globalization. Bioresources, 11:4808-4820.

Hein, S., Lenk, E., Kladtke, J., Kohnle, U., 2007: Effect of crop tree selective thinning on beech (Fagus sylvatica L.) on wood quality, timber assortment and value production. Allgemeine Forst und Jagdzeitung, 178:8-20.

Petráš, R., 2015: Parciálne modely pre rovnocenné hodnotenie rastu a produkcie rovnorodých a zmiešaných porastov. Národné lesnícke centrum - Lesnícky výskumný ústav Zvolen, p. 1-24.

Phonetip, K., Ozarska, B., Brodie, G. I., 2017: Comparing two internal check measurement methods for wood drying quality assessment. European Journal of Wood and Wood Products, 75:139-142.

Popadić, R., Šoškić, B., Milić, G., Todorović, N., Furtula, M., 2014: Influence of the sawing method on yield of beech logs with red heartwood. Drvna industrija, 65:35-42.

Potkány, M., Gejdoš, M., Debnár, M., 2018: Sustainable Innovation Approach for Wood Quality Evaluation in Green Business. Sustainability, 10:2984.

Račko, V., Čunderlík, I., 2006: Qualitative and quantitative evaluation of false heartwood in beech logs of various age and qualitative structure. Wood research, 51:1-10.

Račko, V., Čunderlík, I., 2010: Which of the factors do significantly affect beech false heartwood formation. In: Hardwood Science and Technology, The 4th Conference on Hardwood Research and Utilisation in Europe, p. 94-95.

Shahverdi, M. et al., 2013: The impact of red heartwood on drying characteristics and mass transfer coefficients in beech wood. Austrian Journal of Forest Science, 130:85-101.

STN 480056 Qualitative classification of softwood round timber. 2007, Slovak office of Standards, metrology and testing, Slovakia.

STN EN 844-8 Round and sawn timber. Terminology. Part 8: Terms relating to features of round timber. 1999, Slovak office of Standards, metrology and testing, Slovakia. 